\title{
Guiding dose adjustment of amlodipine after co-administration with ritonavir containing regimens using a physiologically-based pharmacokinetic/pharmacodynamic model
}

\author{
Dwaipayan Mukherjee $^{1} \cdot$ Jiuhong Zha $^{1} \cdot$ Rajeev M. Menon ${ }^{1} \cdot$ Mohamad Shebley $^{1}$
}

Received: 11 October 2017 / Accepted: 23 January 2018 / Published online: 9 February 2018

(C) The Author(s) 2018. This article is an open access publication

\begin{abstract}
Amlodipine, a commonly prescribed anti-hypertensive drug, shows increased systemic exposure with cytochrome P450 (CYP) 3A inhibitors. Ritonavir (RTV) is a potent mechanism-based and reversible CYP3A inhibitor and moderate inducer that is used as a pharmacokinetic enhancer in several antiviral treatment regimens. Drug-drug interaction (DDI) between RTV and amlodipine is due to mixed inhibition and induction of CYP3A4, which is challenging to predict without a mechanistic model that accounts for the complexity of both mechanisms occurring simultaneously. A novel physiologically-based pharmacokinetic (PBPK) model was developed for amlodipine, and the model was verified using published clinical PK and DDI data. The verified amlodipine PBPK model was linked to a pharmacodynamics model that describes changes in systolic blood pressure (SBP) during and after co-administration with RTV. The magnitude and time course of RTV effects on amlodipine plasma exposures and SBP were evaluated, to provide guidance on dose adjustment of amlodipine during and after co-administration with RTV-containing regimens. Model simulations suggested that the increase in amlodipine's plasma exposure by RTV diminishes by approximately $80 \%$ within 5 days after the last dose of RTV. PBPK simulations suggested that resuming a full dose of amlodipine [5 $\mathrm{mg}$ once daily (QD)] immediately after RTV's last dose would decrease daily average SBP by a maximum of $3.3 \mathrm{mmHg}$, while continuing with the reduced dose (2.5 mg QD) for 5 days after the last dose of RTV would increase daily average SBP by a maximum of $5.8 \mathrm{mmHg}$. Based on these results, either approach of resuming amlodipine's full dose could be appropriate when combined with appropriate clinical monitoring.
\end{abstract}

Keywords PBPK · Amlodipine · Systolic blood pressure - CYP3A4 · Dose adjustment · Ritonavir

\section{Introduction}

The calcium-channel blocker amlodipine is a common antihypertensive medication, and was the fifth most prescribed drug in the United States (US) with 57.2 million prescriptions in 2010 [1]. Approximately 50 million adults in the US suffer from hypertension, and for those with co-

Electronic supplementary material The online version of this article (https://doi.org/10.1007/s10928-018-9574-0) contains supplementary material, which is available to authorized users.

Mohamad Shebley

Mohamad.shebley@abbvie.com

1 Clinical Pharmacology and Pharmacometrics, AbbVie Inc., 1 North Waukegan Road, Dept. R4PK, Bldg. AP31-3, North Chicago, IL 60064, USA morbidities, there is a potential for DDI due to polypharmacy [2]. Amlodipine is primarily metabolized and cleared from the body by the drug metabolizing enzyme CYP3A4, with a lesser (10\%) contribution from CYP3A5 [3]. Therefore, co-administering amlodipine with drugs that are strong inhibitors of CYP3A4 may increase the plasma concentrations of amlodipine, where monitoring for symptoms of hypotension and edema in patients become necessary [4]. RTV is a strong CYP3A4 inhibitor and is a used as a pharmacokinetic enhancer in drug combinations with other anti-retrovirals and protease inhibitors such as indinavir, lopinavir, paritaprevir and darunavir [5, 6]. Concomitant administration of RTV-containing regimens with amlodipine may lead to an unintended increase in the plasma exposure of amlodipine and a subsequent drop in blood pressure. The prescribing labels for the direct-acting antiviral (DAA) regimens for the treatment of chronic 
hepatitis $\mathrm{C}$ virus infection, ombitasvir/paritaprevir/RTVplus dasabuvir (3-DAA regimen) [5] or ombitasvir/paritaprevir/RTV (2-DAA regimen) [7] recommend dose reduction of amlodipine by $50 \%$ and to monitor patients for clinical effects of amlodipine. Similarly, the United States Prescribing Information (USPI) for lopinavir/RTV calls for "caution" and "clinical monitoring" when dosed with dihydropyridine calcium-channel blockers which are dependent on CYP3A for metabolism [8]. RTV is a known time-dependent inhibitor and inducer of CYP3A4, and at steady state a net inhibitory effect is observed with sensitive CYP3A substrates [9, 10]. RTV increased amlodipine plasma exposure (AUC) by $89 \%$ (as a combination with indinavir [11]) and 157\% (ombitasvir/paritaprevir/RTV plus dasabuvir [12]). Effects of time-dependent inhibition and induction can outlast RTV's last administered dose and plasma concentrations, until turnover of endogenous CYP3A4 allows the enzyme levels to reach homeostasis again. This raises a question about the duration of the net inhibitory effect on CYP3A4 after the RTV-containing therapy is stopped and when the standard dose of amlodipine can be resumed, which cannot be directly extrapolated due to the complex nature of the reversible and mechanism-based inhibition and induction by RTV.

PBPK models can be of great value for simulation of the various dose regimens and analysis of the dynamic change in plasma concentrations over time for the victim and inhibitor drugs, and relative to the physiological change in abundance of CYP enzymes due to mechanism-based inhibition or induction. These models have been used frequently to simulate drug pharmacokinetics [13-15] and especially in elucidating complex DDI with various comedications, all of which may be impossible to study through dedicated clinical trials [16-18]. PBPK models are often linked with PD models in order to predict changes in drug effect due to extrinsic or intrinsic factors that affect the drug PK, for which a recent example being the work of Moj et al. [19]. Blei [20] developed a PBPK model for amlodipine, but the model did not include CYP3A4-mediated clearance, which is essential in order to model mechanistic DDI with perpetrator drugs. Dennison et al. [21], developed a PBPK model for amlodipine which included CYP3A4-mediated clearance, however their focus was on dissolution and oral absorption of amlodipine. Dennison et al. also assigned the entire oral clearance to be due to CYP3A4 and there was no effort to confirm the contribution of the particular enzyme through DDI with CYP3A4 inhibitors.

The development and verification of a novel PBPK model for amlodipine, and its application in simulating various dose regimens in the presence or absence of RTV are described in this article. The amlodipine PBPK model was linked to a pharmacodynamic (PD) model, which described changes in SBP, in order to inform a clinicallyrelevant dose adjustment for amlodipine during and after co-administration with RTV-containing therapies, e.g., the 3-DAA or 2-DAA regimen.

\section{Methods}

\section{Amlodipine PBPK model development}

A novel PBPK model was developed for amlodipine using information from the literature. Amlodipine is a dihydropyridine base ( $\mathrm{pKa}=9.1)$ [22] and a highly soluble compound (solubility $=0.774 \mathrm{mg} / \mathrm{mL}$ ) [23]. Systemic clearance of amlodipine is primarily mediated by the CYP3A4 enzyme, although a small contribution (10\%) from CYP3A5 has been reported [24]. The contribution of renal clearance in the disposition of amlodipine has been reported to be only 6\% [25]. The PBPK model for amlodipine was developed in Simcyp ${ }^{\circledR}$ version 15R1 simulator (Certara Inc.). The Simcyp software platform $[26,27]$ has been widely used for PBPK modeling and simulation of pharmaceutical compounds by multiple commercial and academic groups, as well as regulatory agencies. Amlodipine physicochemical properties (logP, pKa, molecular weight) and absorption, distribution, metabolism and elimination (ADME) parameters are summarized in Table 1. The ADME parameter values obtained from literature were used as initial estimates in the PBPK model, and a first-order absorption model within Simcyp ${ }^{\circledR}$ was selected based on the available information. Amlodipine is a BCS class I compound with high solubility and permeability $[23,28]$, and absorption rate $\left(k_{a}\right)$ has been reported by Flynn et al. [29]. Stopher et al. [30] found based on a human mass balance study that the entire amount of amlodipine administered orally is absorbed, which suggests that fraction absorbed $\left(f_{a}\right)$ is 1 . Despite its high solubility, amlodipine is reported to have a prolonged oral absorption as suggested by its long time to maximum plasma concentration $\left(\mathrm{T}_{\max }, 6-9 \mathrm{~h}\right)$ [31]. This was captured by optimizing the $k_{a}$ and absorption lag time $\left(t_{\text {lag }}\right)$ based on the observed plasma profile after oral administration [32]. The final optimized value of $k_{a}=0.75$ was very close to that reported by Flynn et al. [29]. Distribution of amlodipine within the body was modeled using a 'minimal PBPK model' available within Simcyp, which models distribution using a central compartment (volume $=\mathrm{V}_{\mathrm{d}}$ ) and a single adjusting compartment (SAC) (volume $=\mathrm{V}_{\mathrm{SAC}}$, blood flow rate $=\mathrm{Q}_{\mathrm{SAC}}$ ). Hepatic distribution and blood flow is also considered separately. Tissue distribution was estimated using tissue-plasma partition coefficients which are estimated in Simcyp V15 using the method of Poulin and Theil [33], corrected by 
Table 1 Physicochemical properties and parameters included in the physiologicallybased pharmacokinetic (PBPK) model for amlodipine

\begin{tabular}{|c|c|c|}
\hline Property/parameter & Value & Source/method \\
\hline \multicolumn{3}{|l|}{ Initial estimates } \\
\hline Mol. weight & $408.88 \mathrm{~g} / \mathrm{mole}$ & www.drugbank.ca \\
\hline Fraction unbound (plasma) & 0.025 & Drug label [4] \\
\hline $\log \mathrm{P}$ (n-octanol:water) & 2.96 & Caron et al. [22] \\
\hline Blood:Plasma ratio & 0.596 & Simcyp ${ }^{\circledR}$ prediction toolbox \\
\hline pKa (base) & 9.1 & Caron et al. [22] \\
\hline Absorption rate constant & $\mathrm{k}_{\mathrm{a}}=0.8 \mathrm{~h}^{-1}$ & Flynn et al. [29] \\
\hline Fraction absorbed & $\mathrm{f}_{\mathrm{a}}=1$ & \\
\hline Volume of distr. & $\mathrm{V}_{\mathrm{d}}(\mathrm{IV})=21.4 \mathrm{~L} / \mathrm{kg}$ & Faulkner et al. [32] \\
\hline Vol. of SAC & $\mathrm{V}_{\mathrm{SAC}}=6.38 \mathrm{~L} / \mathrm{kg}$ & Park et al. [41] \\
\hline Flow rate into $\mathrm{SAC}$ & $\mathrm{Q}_{\mathrm{SAC}}=102 \mathrm{~L} / \mathrm{h}$ & \\
\hline Metabolism & CYP3A4 (10\% CYP3A5) & Zhu et al. [24] \\
\hline \multirow[t]{2}{*}{ Elimination } & $6 \%$ renal clearance & Beresford et al. [25] \\
\hline & 33.9 L/h (IV clearance) & Faulkner et al. [32] \\
\hline \multicolumn{3}{|l|}{ Optimized parameters } \\
\hline Absorption rate constant & $0.75 \mathrm{~h}^{-1}$ & Optimized based on oral PK \\
\hline Absorption lag time & $3.2 \mathrm{~h}$ & \\
\hline Fraction unbound in gut & 0.2 & \\
\hline $\mathrm{V}_{\mathrm{SAC}}$ & $11 \mathrm{~L} / \mathrm{kg}$ & \\
\hline $\mathrm{Q}_{\mathrm{SAC}}$ & $90 \mathrm{~L} / \mathrm{h}$ & \\
\hline CYP3A4 intrinsic clearance & $\mathrm{CL}_{\mathrm{int}}=170 \mathrm{~L} / \mathrm{h}$ & Optimized based on oral PK and DDI \\
\hline CYP3A5 intrinsic clearance & $\mathrm{CL}_{\mathrm{int}}=43.5 \mathrm{~L} / \mathrm{h}$ & Estimated relative to $\mathrm{CYP} 3 \mathrm{~A} 4^{\mathrm{a}}{ }^{[24]}$ \\
\hline Biliary clearance & $12 \mathrm{~L} / \mathrm{h}$ & Optimized based on oral PK \\
\hline Renal clearance & $1.8 \mathrm{~L} / \mathrm{h}$ & Based on $6 \%$ of total CL [25] \\
\hline Non-specific clearance & $16 \mathrm{~L} / \mathrm{h}$ & Optimized based on oral PK \\
\hline
\end{tabular}

SAC single adjusting compartment

${ }^{\mathrm{a}}$ Based on intrinsic clearance due to CYP3A4 and relative contribution of CYP3A5 and also the relative differences in the abundances of CYP3A4 and CYP3A5 in the gut and in the liver
Berezhkovsky et al. [34] Other parameters of the model were optimized using 'top-down' optimization based on published clinical PK data (plasma concentrations) of amlodipine in healthy volunteers. Clinical data for model optimization were obtained from Faulkner et al. [32], which comprised mean plasma concentration data for 12 healthy volunteers after intravenous (IV) and oral doses of amlodipine. The PBPK model was optimized using the 'fasted' state for the oral dose and the IV dose (constant rate IV infusion of $10 \mathrm{~min}$ ) in accordance with the clinical study design by Faulkner et al. [32]. For parameter optimization within Simcyp V15, the Nelder-Mead algorithm with the sum of weighted least squared errors as the objective function was used. Since CYP3A4 is the major elimination pathway for amlodipine and is the cause for DDI with various CYP3A perpetrator drugs, amlodipine intrinsic clearance parameters for CYP3A4 were further optimized using clinical DDI data $\left(\mathrm{C}_{\max }\right.$ and AUC ratios). The DDI study that was used for optimization involved coadministration of amlodipine with a combination of indinavir and RTV in 18 healthy, HIV-seronegative adults. In the study by Glesby et al., [11] amlodipine was dosed alone at $5 \mathrm{mg}$ QD for 7 days initially. This was followed by dosing of indinavir + RTV (800 mg twice daily [BID]/ $100 \mathrm{mg}$ BID) for 19 days (Day 8-Day 26) and amlodipine (5 mg QD) on Day 20-Day 26. Plasma PK was measured on Day 7 and again on Day 26. A schematic representation of the study design is included in the supplementary information (Figure S1). A Comparison of PK parameters (maximum plasma concentration, $\mathrm{C}_{\max }$, and area under the plasma-concentration time curve from time 0 to $24 \mathrm{~h}$, $\mathrm{AUC}_{24}$ ) on Day 7 and Day 26 was carried out to quantify the effect of steady-state RTV on steady-state levels of amlodipine. The PBPK model simulated a trial design identical to the original clinical study by Glesby et al. [11]. A PBPK model for RTV was developed by Shebley et al. [35] incorporating reversible, time-dependent and mechanism-based inhibition and induction of CYP3A4. The RTV PBPK model was used as reported in Shebley et al. for the purpose of simulating DDI with amlodipine. The 
contribution of CYP3A4 to amlodipine clearance was optimized by optimizing the values of $V_{\max }$ and $K_{m}$ for CYP3A4 and by assigning additional clearance to biliary and non-specific pathways. Simcyp ${ }^{\circledR}$ incorporates population characteristics for healthy volunteers and includes observed population distributions of physiological parameters including tissue volumes, blood flow rates, metabolizing enzyme abundances, etc. [26]. These values have been obtained from multiple references and are summarized by multiple Simcyp-specific publications. [36-38]. Enzyme expression and turnover values for specific enzymes including CYP3A4/3A5 are built-in within the Simcyp simulator and these have been verified/validated in multiple instances separately [39, 40]. The "population representative" virtual healthy volunteer was used within Simcyp ${ }^{\circledR}$ for the optimization of model parameters.

\section{Amlodipine PBPK model verification}

The PBPK model was verified against data (plasma concentrations) from the oral multiple dosing arm in the study by Faulkner et al. [32] involving healthy volunteers. Amlodipine was administered at $15 \mathrm{mg}$ QD for 14 days to 28 healthy subjects. The developed PBPK model was verified using 3 external verification data sets (comprising plasma concentration values) of amlodipine PK (summarized in Table 2) [28, 42, 43]. For verification, the PBPK model was used to simulate plasma concentrations in 100 virtual individuals (10 trials of 10 subjects each). The model was additionally verified using clinical DDI data $\left(\mathrm{C}_{\max }\right.$ and AUC ratios) with RTV (ombitasvir/paritaprevir/
RTV + dasabuvir) from Menon et al. [12]. This study involved an amlodipine single dose of $5 \mathrm{mg}$ on day 1 , followed by a 10 day washout, RTV multiple dose administration of $100 \mathrm{mg}$ QD and then another amlodipine dose of $5 \mathrm{mg}$ at RTV steady state. Schematic representations of the study design have been included in the supplementary information (Figure S1). The model acceptance criterion was pre-specified as a $20 \%$ prediction error relative to the observations, consistent with the bioequivalence criteria (80-125\%) for PK metrics [44]. This means that the ratio of the model predicted value of a $\mathrm{PK}$ parameter $\left(\mathrm{C}_{\max }\right.$ or AUC) to the observed PK parameter value must fall within the 0.8-1.25 range to be acceptable. A local sensitivity analysis of the final PBPK model was also carried out, considering $\mathrm{C}_{\max }$ and $24 \mathrm{~h}$ AUC as the output variables. Parameters of the PBPK model were varied from 0.1 to 10 fold of their nominal values using the sensitivity analysis tool within Simcyp V15.

\section{Amlodipine PBPK model application: RTV DDI prediction}

The developed and verified PBPK model was used to simulate multiple dosing of amlodipine when co-administered with the RTV-containing 3-DAA regimen [5]. As RTV is the only clinical inhibitor and inducer of CYP3A4 within the regimen, only RTV was simulated as a surrogate for the DAA regimen. Amlodipine at $5 \mathrm{mg}$ QD alone was simulated for 14 days to reach steady state, followed by the combination of $100 \mathrm{mg}$ QD RTV and $2.5 \mathrm{mg}$ QD amlodipine for an additional 14 days. The $50 \%$ reduced

Table 2 Summary of published clinical studies used for obtaining mechanistic information and for model optimization and validation

\begin{tabular}{|c|c|c|c|}
\hline Study & Population & Information/Results & Source \\
\hline IV and oral single dose PK study & 12 healthy subjects & PK parameters optimized & Faulkner et al. [32] \\
\hline Renal impairment study & 27 renally impaired subjects & No significant changes & Laher et al. [45] \\
\hline IV and oral ${ }^{14} \mathrm{C}$ study & 2 healthy subjects & Renal clearance optimized & Beresford et al. [25] \\
\hline DDI study with Indinavir + RTV & $\begin{array}{l}18 \text { healthy HIV-negative } \\
\text { subjects }\end{array}$ & Model optimization & Glesby et al. [11] \\
\hline Multiple oral dose study & 28 healthy subjects & Model verification & Faulkner et al. [32] \\
\hline $\begin{array}{l}\text { PK study with increasing doses of } \\
\text { amlodipine }\end{array}$ & 12 healthy subjects & Model verification & Williams and Cubeddu [43] \\
\hline Amlodipine PK study & 24 healthy subjects & Model verification & Rausl et al. [28] \\
\hline Food effect study & 6 healthy subjects & Model verification & Faulkner et al. [42] \\
\hline DDI study with Viekira Pak & 14 healthy subjects & Model verification & Menon et al. [12] \\
\hline PopPK/PD study for amlodipine & 73 subjects with hypertension & $\begin{array}{l}\text { Direct-effect PD model } \\
\text { development }\end{array}$ & $\begin{array}{l}\text { New drug application for } \\
\text { amlodipine [3] }\end{array}$ \\
\hline 6 week PK/PD study & 12 subjects with hypertension & $\begin{array}{l}\text { Indirect-effect PD model } \\
\text { development }\end{array}$ & Donnelly et al. [46] \\
\hline
\end{tabular}

$I V$ intravenous, $P K$ pharmacokinetic, $D D I$ drug-drug interaction, $R T V$ ritonavir, $p o p P K$ population pharmacokinetic, $P D$ pharmacodynamic 
amlodipine dose was in accordance with labelling recommendations for the DAA regimens. After this 28-day schedule, 2 different dose regimens were simulated. In the first regimen, amlodipine at a reduced dose (2.5 $\mathrm{mg}$ QD) was continued for 5 additional days after the last dose of RTV, followed by a return to a full ( $5 \mathrm{mg}$ QD) dose of amlodipine. In the second regimen, the regular dose of amlodipine (5 mg QD) was resumed immediately after the last dose of RTV.

\section{Amlodipine PD model development}

A PD model that describes the effects of amlodipine on SBP was developed to link the dynamic plasma concentration of amlodipine with SBP, in order to understand the effect of DDI on clinical outcomes. Studies have shown that it is more important to control SBP than diastolic blood pressure [47], and SBP was found to be the best single predictor of cardiovascular disease and coronary heart disease in multiple trials [47-49]. Amlodipine is a calciumchannel blocker that causes systemic vasodilation, helping in the management of hypertension. Due to the long halflife of amlodipine ( $\sim 40 \mathrm{~h}$ ), a single dose of amlodipine is effective in reducing SBP over $24 \mathrm{~h}$ [50]. Thus SBP was selected as the endpoint in the PD model. It is also well known that blood pressure along with heart rate has a pronounced circadian rhythm, characterized by substantial reductions during sleep, a rapid increase after awakening, and variability during the day $[51,52]$. The diurnal variation is an important consideration in the clinical management of hypertension and cardiovascular disease [52] and hence it was included in the PD model as a baseline effect.

Two previously published PD models for amlodipine were initially considered: a direct-effect model [3] and an indirect-effect model [46]. The direct-effect model is a regression equation model based on clinical observations for amlodipine [3], and it relates SBP to daily average plasma concentrations of amlodipine. The indirect-effect model developed by Donnelly et al. [46] considers an additional effect compartment that takes into account the delay between amlodipine plasma exposure and the lowering of blood pressure (Eq. 1):

$S B P=S B P_{0}+m \cdot C \cdot \exp \left(-k_{e o} t\right)$

where, $S B P_{O}$ is the baseline systolic blood pressure in $\mathrm{mmHg}, C$ is the dynamic plasma concentration of amlodipine in $\mathrm{ng} / \mathrm{mL}, k_{e o}$ is the elimination rate constant from the effect compartment, $t$ is time after first dose in hours, and $m$ is a first-order rate constant. The indirecteffect model, which uses dynamic plasma concentration, was used to model the effect of amlodipine on changing SBP. The model was fitted to mean SBP from 12 hypertensive patients reported by Donnelly et al. [46]. $S B P_{O}$ is not constant and has significant diurnal variability, as discussed earlier. Circadian rhythms in baseline models have been developed by Sällström et al. [53] for body temperature, heart rate, and blood pressure regulation, where oscillatory functions have been used to capture dynamic changes in the baseline value of the relevant variable. Accordingly, a cosine function was fitted to the clinical SBP data in the placebo and drug arms from Donnelly et al. [46], with a time shift as shown in Gabrielsson and Weiner [54]. The dynamic baseline model developed here can be represented as Eq. 2:

$S B P_{0}=P_{0}+A \cdot \cos \left(\frac{2 \pi f}{24} T\right)$

where, $P_{O}$ is the initial SBP at the beginning of the day, $A$ is the amplitude of the circadian variation, $f$ is the frequency of SBP oscillation, $\mathrm{T}$ is the 24-h clock time and is calculated as: $\mathrm{T}=$ time after first dose-number of full days elapsed $\times 24$. The parameters in Eq. (2) were estimated by fitting the equation to clinical SBP measurements after administration of placebo as described by Donnelly et al. The fitting was performed using MATLAB 2016b (using the fminsearch function which uses the Nelder-Mead optimization algorithm) and the final fitted parameters are summarized in Table 3. The parameters in Eq. (1) were fitted using clinical SBP measurements at Day 1 and Day 43 after a daily dose of $5 \mathrm{mg}$ of amlodipine as described by Donnelly et al. The final fitted parameters are summarized in Table 3. It should be noted that the PD parameters used in the indirect-effect model were fitted to a hypertensive population data as described by Donnelly et al. [46] and there was high inter-individual variability associated with parameter values $m$ and $k_{e o}$. Since only the mean observations were reported in Donnelly et al., the model parameters were fitted to the mean data only. The complete PD model combining Eqs. (1) and (2) can be represented as follows:

$S B P=P_{0}+A \cos \left(\frac{2 \pi f}{24} T\right)+m C \exp \left(-k_{e o} t\right)$

The PD model (shown in Eq. (3)) was implemented in Simcyp $^{\circledR}$ V15 in order to form an integrated PBPK/PD model. The PD model was incorporated as a 'custom PD' module using the Lua scripting feature in Simcyp ${ }^{\circledR}$ as described in Abduljalil et al. [55]. The relevant Lua script is provided in the supplementary information as Figure S2.

\section{Amlodipine PBPK/PD model application}

The developed PBPK/PD model was used to simulate the changes in SBP due to the dynamic changes in amlodipine 
Table 3 Fitted parameter values for the pharmacodynamics model for amlodipine

\begin{tabular}{llll}
\hline Parameter & Symbol & Value & Residual error $^{c}$ \\
\hline Baseline model $^{\mathrm{a}}$ & & & 2.89 \\
Initial pressure & $P_{o}$ & $148.8 \mathrm{mmHg}$ & \\
Circadian amplitude & $A$ & $8.25 \mathrm{mmHg}$ & \\
Circadian frequency & $f$ & $1.76 \mathrm{day}^{-1}$ & 5.04 \\
Drug effect model & & & \\
Direct effect rate & $m$ & $-3.145 \mathrm{mmHg} \cdot \mathrm{mL} / \mathrm{ng}$ & \\
Indirect effect rate constant & $k_{e o}$ & $0.049 \mathrm{~h}^{-1}$ & \\
\hline
\end{tabular}

${ }^{a}$ Baseline circadian rhythm model for SBP

${ }^{\mathrm{b}}$ Drug effect model on SBP

${ }^{\mathrm{c}}$ Residual error estimated as $\sqrt{\frac{\sum\left(y-y^{\prime}\right)^{2}}{N}}$, where y and y' represent the observed and predicted values of SBP respectively plasma exposures with and without RTV. Three clinical scenarios were simulated for comparing the effect on SBP. In scenario 1, model simulations were carried out with RTV, with and without dose adjustment of amlodipine, to understand the effect of dose adjustment on SBP. Amlodipine PK was simulated after a regular dose of $5 \mathrm{mg}$ QD and a RTV dose of $100 \mathrm{mg}$ QD starting on day 14 and continuing for 14 days. In one simulation, the amlodipine dose was continued at $5 \mathrm{mg}$ QD during coadministration with RTV. In the other simulation, the amlodipine dose was reduced by $50 \%$ (to $2.5 \mathrm{mg}$ QD) during coadministration with RTV. In scenario 2, two simulations of dose adjustment were performed. In the first simulation, the reduced amlodipine dose of $2.5 \mathrm{mg}$ QD was continued for 5 additional days after the last dose of RTV. In the other simulation, the regular amlodipine dose was resumed immediately after RTV was stopped. Scenario 3 is similar in design to scenario 2, but the effect of a higher amlodipine dose (10 mg QD, the maximum dose per the USPI [4]) was simulated. All model simulations were carried out using a virtual population representative within Simcyp $^{\circledR}$.

\section{Results}

\section{Single and multiple dose pharmacokinetics of amlodipine}

The optimized PBPK model resulted in a good agreement between observed and predicted values for amlodipine IV (Fig. 1a) and oral (Fig. 1b) PK profiles after single dose administration. The model predictions of amlodipine $\mathrm{C}_{\max }$ and area under the concentration-time curve extrapolated to infinity $\left(\mathrm{AUC}_{\propto}\right)$ were within an $18 \%$ prediction error as shown in Table 4, and consistent with the pre-specified acceptance criterion of a $20 \%$ prediction error. Figure 1c shows the simulated amlodipine concentration-time profile following multiple dose administration of amlodipine alone at $15 \mathrm{mg}$ QD (14 doses) with plasma concentrations measured over 20 days (multiple dose study from Faulkner et al. [32]). The predicted plasma concentration of amlodipine reached steady state at around 7 days, consistent with the reported observations [31]. The PBPK model predicted an accumulation ratio for $C_{\max }$ (Day 14:Day1) of 2.1 compared with the observed value of 2.6 (observed range $0.9-5.7$ ), and an accumulation ratio of the minimum plasma concentration $\left(\mathrm{C}_{\min }\right)$ (Day14:Day1) of 2.9, compared with the observed value of 3.6 (observed range 1.6-11.7). The model-predicted accumulation ratio of $\mathrm{AUC}_{24}$ (Day14:Day1) was 2.9, compared with the observed value of 3.2 (observed range 1.2-7.4). Figure 2 shows the model predictions of 10 trials each consisting of 10 virtual subjects. The 5 and $95 \%$ predicted percentiles of the plasma concentrations included all of the observed data from 3 different clinical trials. The PBPK model predictions of amlodipine plasma concentrations following single and multiple dosing were consistent with the clinically observed data and met the model acceptance criteria. Sensitivity analysis results from a local sensitivity analysis are presented in the Supplementary Information (Figure S6).

\section{Amlodipine-RTV DDI}

Simulations of DDI with RTV were compared to clinical data $\left(\mathrm{C}_{\max }\right.$ and AUC ratios) from the published reports by Glesby et al. [11] and Menon et al. [12] Table 4 summarizes the PBPK model predictions versus the observed $\mathrm{C}_{\max }$ and AUC ratios of amlodipine with and without RTV. The PBPK model results met the pre-specified acceptance criteria, with a maximum prediction error of $13 \%$ compared with clinical data. The final PBPK model was used to simulate amlodipine plasma PK after co-administration 

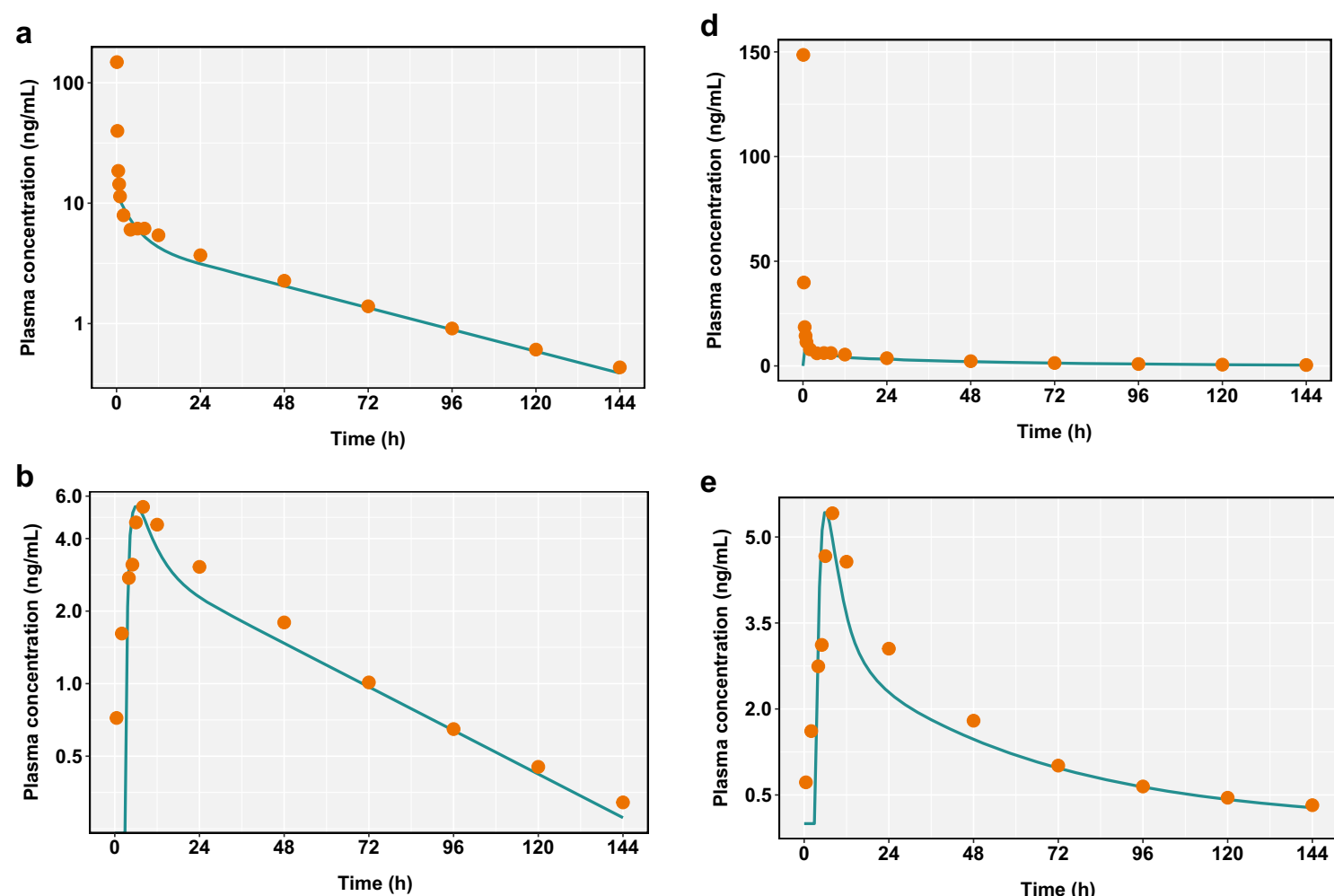

e



C

f

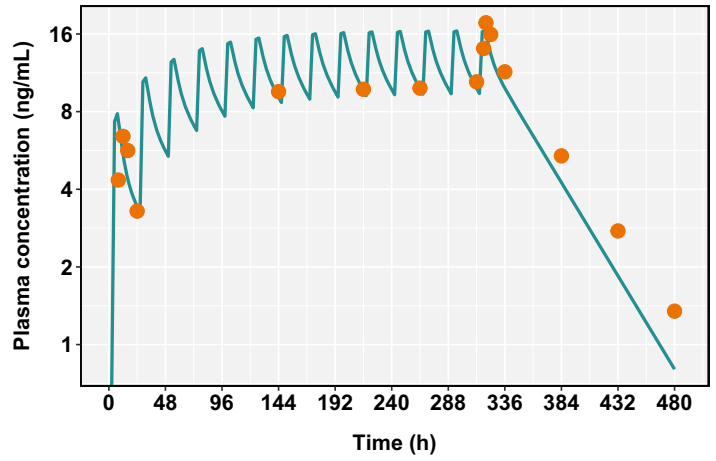

Fig. 1 Comparison of physiologically-based pharmacokinetic (PBPK) model predictions (blue lines) of plasma concentrations of amlodipine after a a $10 \mathrm{mg}$ intravenous (IV) infusion, b a $10 \mathrm{mg}$ oral dose, and c multiple amlodipine dosing of $15 \mathrm{mg}$ once daily (QD) for 14 days. The model shows plasma concentrations to reach steady

with RTV over time. Figure 3 shows the simulated $\mathrm{C}_{\max }$ and $\mathrm{AUC}_{24}$ ratios over time from day 15 onwards, when RTV dosing was started (simulated dosing schedule discussed in the Methods section). Both the $\mathrm{C}_{\max }$ and $\mathrm{AUC}_{24}$ ratios increased due to CYP3A4 inhibition by RTV and the interaction reached steady state on approximately Day 25 . After the last dose of RTV on Day 28, the $\mathrm{C}_{\max }$ and AUC ratios of amlodipine started to decrease until amlodipine plasma exposures reached baseline levels $\left(\mathrm{C}_{\max }\right.$ and $\mathrm{AUC}$ ratios of 1.0). As shown in Fig. 3, the DDI ratios reached 1.2 on Day 34 , suggesting that $80 \%$ of the CYP3A4

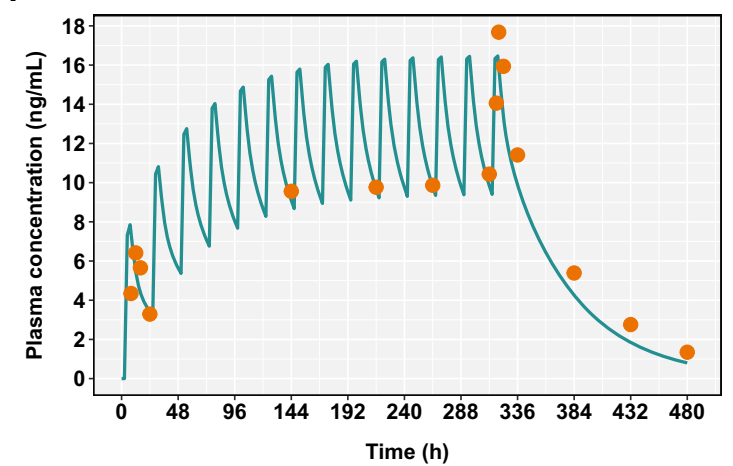

state in about 7 days. $\mathbf{d}, \mathbf{e}$, and $\mathbf{f}$ represent the same plots with linear $\mathrm{y}$-axes. Clinical data (mean of 12 subjects for single dose studies and 28 subjects for the multiple dose study) from Faulkner et al. [32] are represented as orange dots (Color figure online)

inhibition by RTV was resolved within 5 days after the last dose of RTV.

\section{Amlodipine PD model verification}

Figure 4 shows the model-predicted mean SBP compared with the mean observations from 12 hypertensive patients [46]. The predictions are for a 'population representative' male subject from the age group of 25-64 years in Simcyp $^{\circledR}$ V15R1. The model predictions successfully captured the circadian variation in SBP and also the decrease in SBP due to amlodipine administration based on visual 
Table 4 Comparison of model predicted and clinically observed pharmacokinetic parameters (Results are for a population representative virtual subject for all studies used for optimization, except Menon et al., which is verification in a virtual population of 100 subjects)

\begin{tabular}{|c|c|c|c|c|}
\hline Clinical study & PK parameter & Prediction & Observation & Pred:obs Ratio \\
\hline \multirow[t]{2}{*}{ Faulkner et al. (IV) [32] } & $\mathrm{AUC}_{\propto}(\mathrm{ng}-\mathrm{h} / \mathrm{mL})$ & 303 & 371 & 0.82 \\
\hline & $t_{1 / 2}(h)$ & 39.9 & 33.8 & 1.18 \\
\hline \multirow[t]{5}{*}{ Faulkner et al. (oral) [32] } & $\mathrm{AUC}_{\propto}(\mathrm{ng}-\mathrm{h} / \mathrm{mL})$ & 201 & 238 & 0.84 \\
\hline & $\mathrm{C}_{\max }(\mathrm{ng} / \mathrm{mL})$ & 5.45 & 5.9 & 0.92 \\
\hline & $\mathrm{T}_{\max }(\mathrm{hr}$.) & 6.09 & 7.6 & 0.8 \\
\hline & $\mathrm{t}_{1 / 2}(\mathrm{~h})$ & 39.9 & 35.7 & 1.12 \\
\hline & $\mathrm{F}(\%)$ & 66.6 & 64 & 1.04 \\
\hline \multirow[t]{2}{*}{ Glesby et al. ${ }^{\mathrm{a}}$ (DDI) [11] } & $\mathrm{C}_{\max }$ ratio & 1.74 & 1.82 & 0.96 \\
\hline & $\mathrm{AUC}_{24}$ ratio & 1.89 & 1.89 & 1.0 \\
\hline \multirow[t]{2}{*}{ Menon et al. ${ }^{\mathrm{b}}$ (DDI) [12] } & $\mathrm{C}_{\max }$ ratio & $1.42(1.39-1.45)$ & $1.26(1.11-1.44)$ & 1.13 \\
\hline & $\mathrm{AUC}_{\propto}$ ratio & $2.28(2.19-2.38)$ & $2.57(2.31-2.86)$ & 0.89 \\
\hline
\end{tabular}

$I V$ intravenous, DDI drug-drug interaction

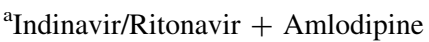

${ }^{\mathrm{b}}$ Ombitasvir/Paritaprevir/Ritonavir + Dasabuvir + Amlodipine
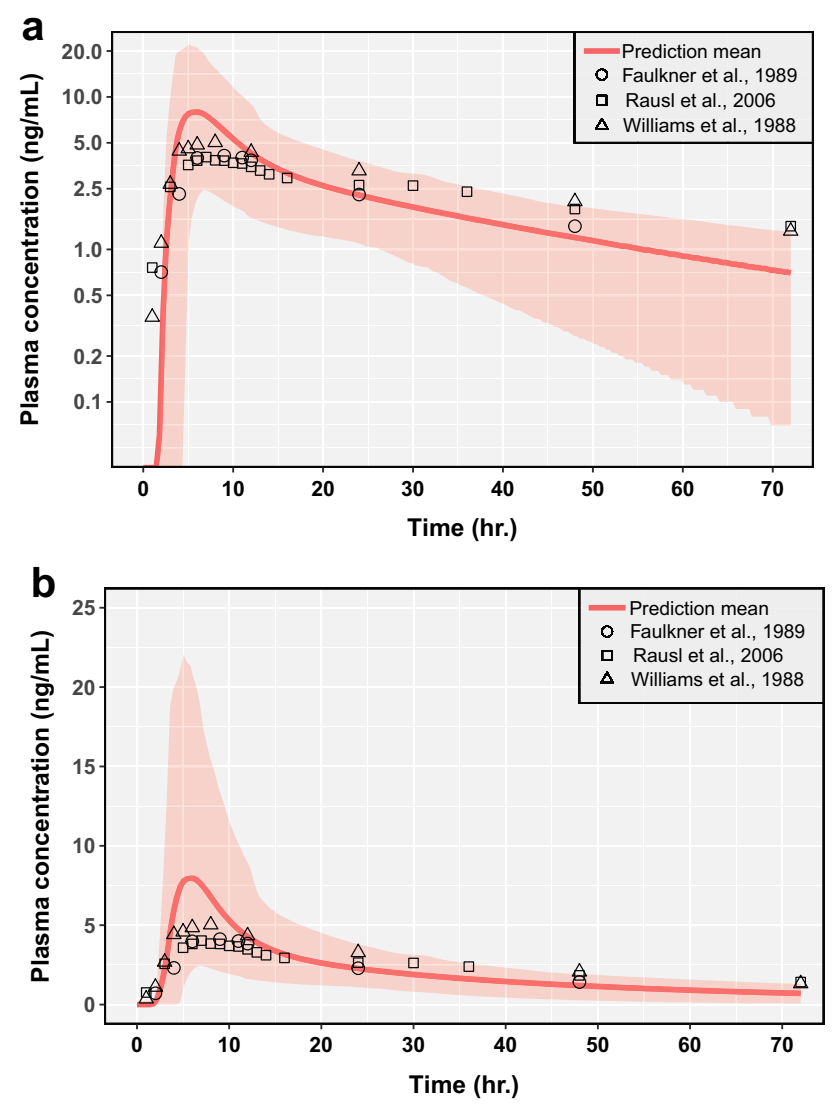

Fig. 2 Comparison of physiologically-based pharmacokinetic (PBPK) model predictions of 100 virtual subjects (10 trials of 10 subjects each) with clinical observations across multiple studies after a single amlodipine oral dose of $10 \mathrm{mg}$, shown with a $\log \mathrm{y}$-axis (a) and a linear $y$-axis (b). The $\mathrm{Y}$ axis shows the plasma concentrations of amlodipine. The red line represents the prediction mean and the red shaded area represents the 5th-95th percentiles of the predictions (Color figure online)

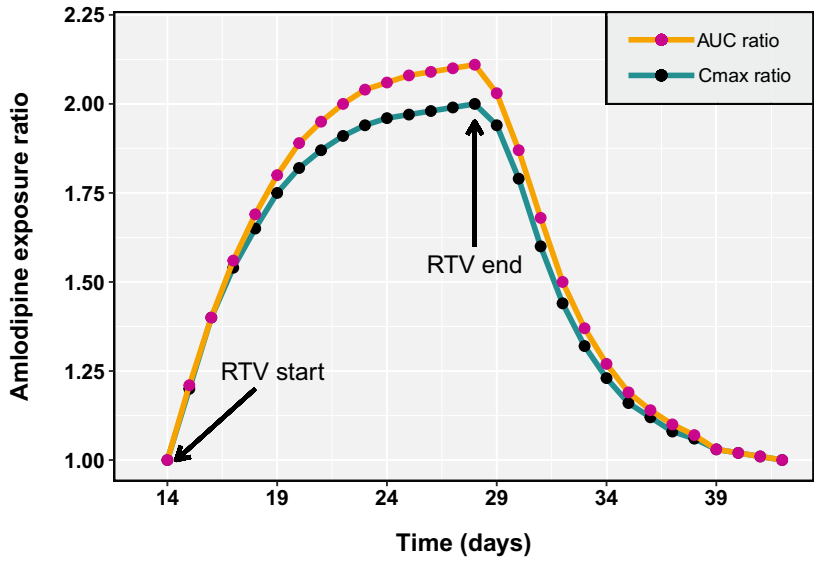

Fig. 3 Model prediction of time-based changes in the drug-drug interaction (DDI) magnitude of amlodipine and ritonavir (RTV) over multiple days after amlodipine [2.5 mg once daily (QD)] + RTV (100 mg QD) co-dosing for 14 days (Day 15-Day 28), followed by continuation of amlodipine (2.5 mg QD) alone. This was preceded by amlodipine $(2.5 \mathrm{mg}$ QD) dosing for 14 days. The area under the plasma-concentration time curve from time 0 to $24 \mathrm{~h}\left(\mathrm{AUC}_{24}\right)$ ratio (orange line) and maximum plasma concentration $\left(\mathrm{C}_{\max }\right)$ ratio (blue line) of amlodipine were estimated with respect to steady-state (Day 14) values as reference. (RTV start indicates starting of co-administration of RTV; RTV stop indicates RTV stoppage) (Color figure online)

inspection of the simulated versus observed data. As shown in Fig. 4, the model simulated curves are not in complete agreement with the observations. This might be due to the fact that the simple PD model developed here might not be sufficient to capture effects on blood pressure due to other physiological mechanisms such as circadian effects on blood pressure. 


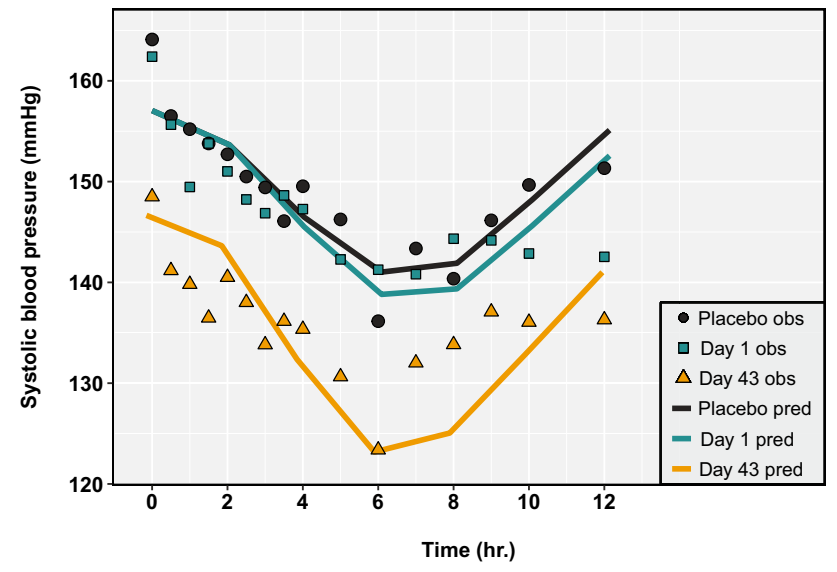

Fig. 4 Comparison of model predicted systolic blood pressure (SBP) compared with mean clinical observations from day 1 and day 43 for patients on a $5 \mathrm{mg}$ once daily (QD) regimen of amlodipine or placebo for 6 weeks (data from Donnelly et al. [46]). Symbols represent observed values for placebo (triangle), Day 1 (square), and Day 43 (circle); lines represent predicted values for placebo (black), Day 1 (blue), and Day 43 (orange) (Color figure online)

\section{Amlodipine-RTV PBPK/PD model simulations}

The PBPK/PD model was used to simulate the changes in SBP due to the dynamic changes in amlodipine plasma exposures in three separate model simulation scenarios (discussed in detail in the Methods section). Figure 5 shows the results from scenario 1 , where the effect of dose adjustment of amlodipine was compared with no dose adjustment.
As shown in Fig. 5a, dose adjustment of amlodipine during RTV coadministration was sufficient to maintain amlodipine plasma concentrations at the same level as without RTV. Figure $5 \mathrm{~b}$ shows that with dose adjustment, SBP was maintained at similar levels as before RTV coadministration. Interestingly, without amlodipine dose adjustment, the predicted SBP dropped to below $110 \mathrm{mmHg}$ at some time points throughout the course of amlodipine administration. Figure 6 shows the results from scenario 2. The simulations suggested that continuing the reduced amlodipine dose ( $2.5 \mathrm{mg}$ QD) for an 5 additional days results in a lowering of amlodipine plasma concentrations and a corresponding increase in SBP over the 5 days to $149.9 \mathrm{mmHg}$.

Simulations using the PBPK/PD model suggested that continuing an amlodipine reduced dose of $2.5 \mathrm{mg}$ QD for 5 days after the last dose of RTV results in a slight increase in the daily average SBP to a maximum of $5.8 \mathrm{mmHg}$ above that predicted on the last day of RTV coadministration (Fig. 6b). In contrast, resuming an amlodipine full dose of $5 \mathrm{mg}$ QD immediately after the last dose of RTV results in a decrease of daily average SBP by a maximum of $3.3 \mathrm{mmHg}$ below that predicted on the last day of RTV coadministration (Fig. 6b). Figure 7 shows results from scenario 3, where a similar comparison was done for a higher amlodipine dose level of $10 \mathrm{mg}$ QD. The simulation results suggested that continuing an amlodipine reduced dose $(5 \mathrm{mg}$ QD in this case) results in an increase of $10.6 \mathrm{mmHg}$, while switching immediately to the regular dose results in a decrease of $6.5 \mathrm{mmHg}$.
Fig. 5 Results for Scenario $1-$ Predicted plasma concentration of amlodipine (AML) (a) and systolic blood pressure (b) using a physiologically-based pharmacokinetic (PBPK)/ pharmacodynamic (PD) model for a ritonavir (RTV)amlodipine once daily (QD) dosage regimen with (green line) and without (pink line) amlodipine dose adjustment (Color figure online)

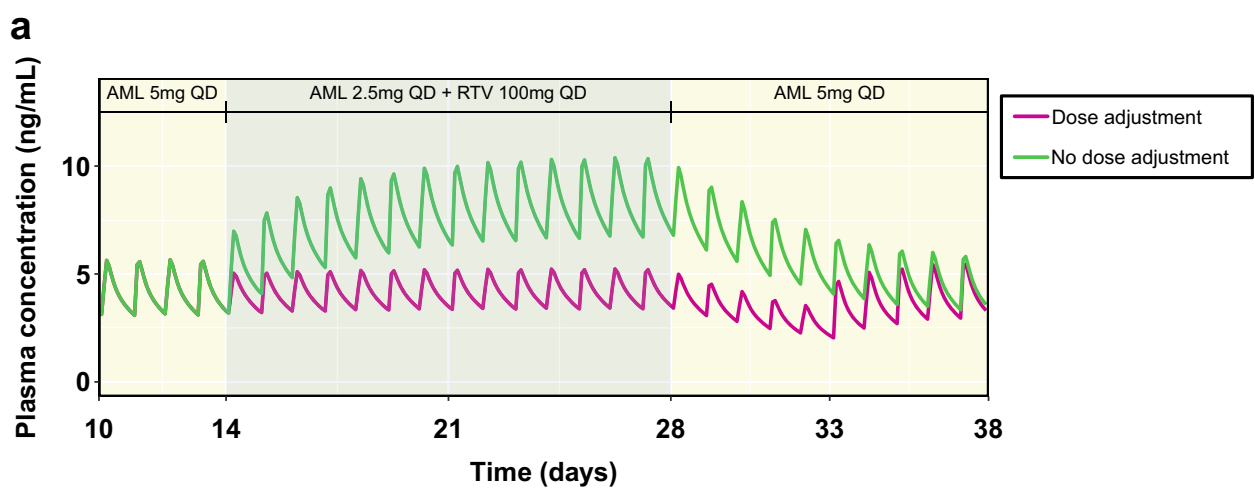

b

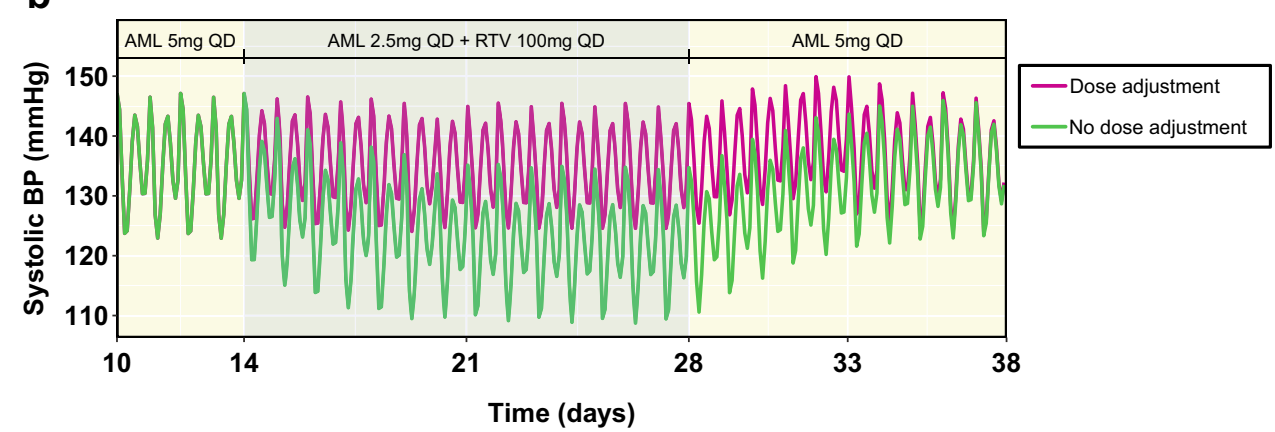


Fig. 6 Results for Scenario 2Predicted plasma concentration of amlodipine (a) and daily averaged systolic blood pressure (b) using a physiologicallybased pharmacokinetic (PBPK)/ pharmacodynamic (PD) model for a ritonavir (RTV)-

amlodipine dose regimen with a regular amlodipine dose $(5 \mathrm{mg}$ once daily [QD]) starting 5 days after RTV stoppage (green line) and a regular amlodipine dose starting immediately after RTV stoppage (pink line) (Color figure online)

Fig. 7 Results for Scenario 3 Predicted plasma concentration of amlodipine (a) and daily averaged systolic blood pressure (b) using a physiologicallybased pharmacokinetic (PBPK)/ pharmacodynamic (PD) model for a ritonavir (RTV)amlodipine dosage regimen with a regular amlodipine dose (10 mg once daily [QD]) starting 5 days after RTV stoppage (green line) and a regular amlodipine dose starting immediately after RTV stoppage (pink line) (Color figure online)

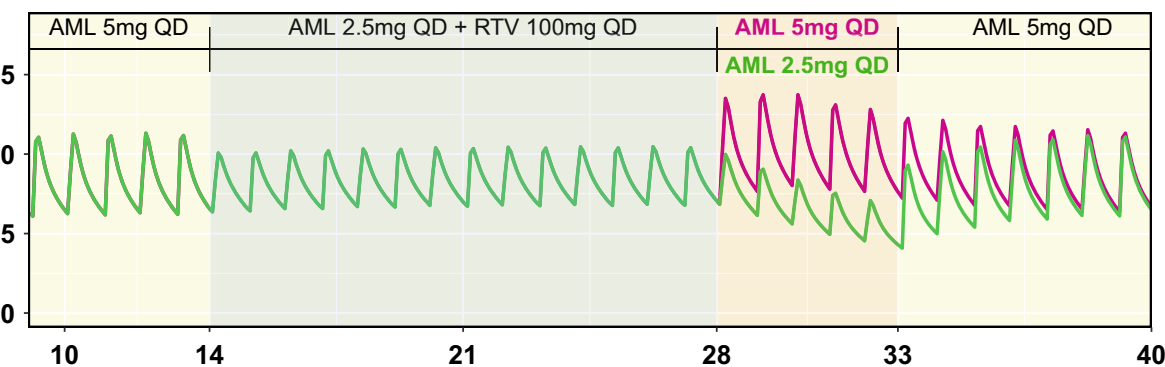

Time (days)

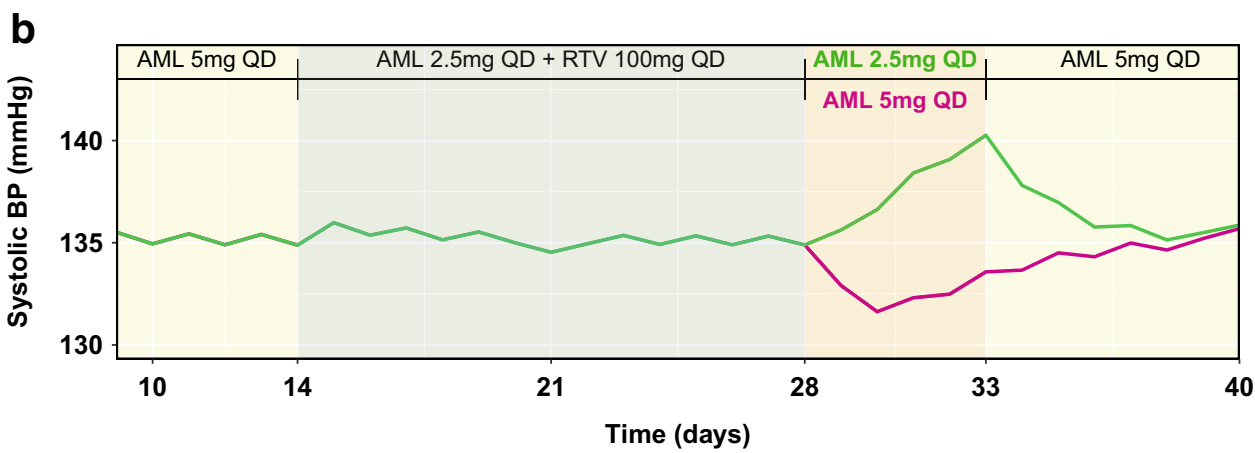

a

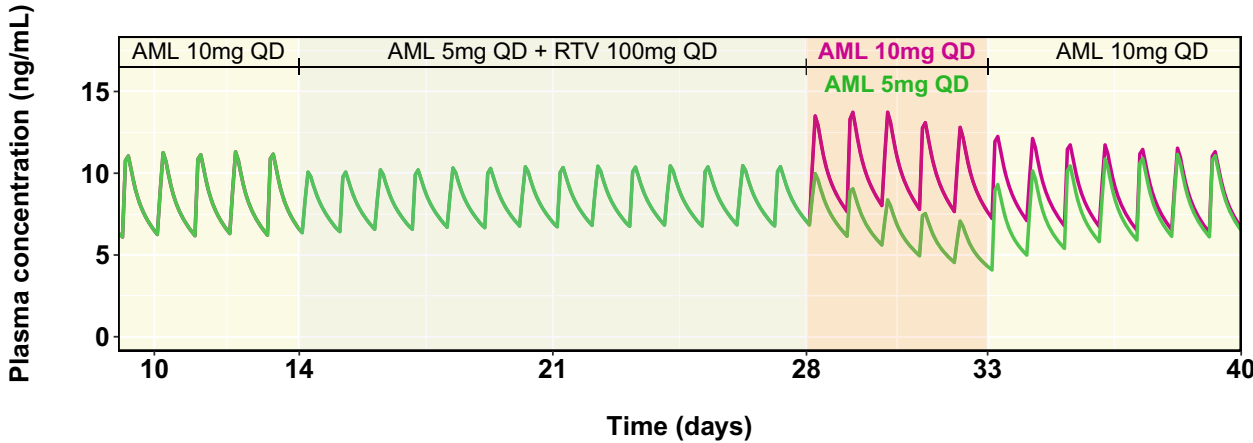

b

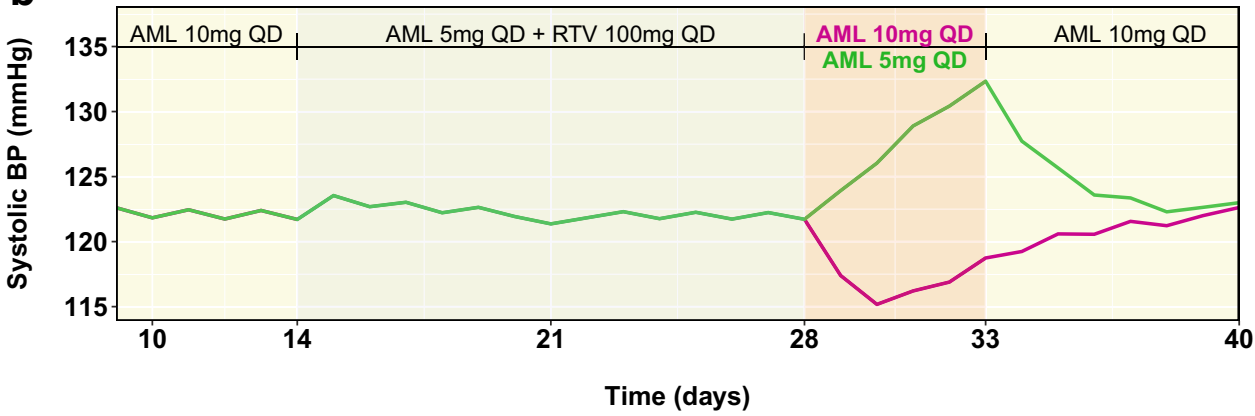




\section{Discussion}

A PBPK/PD modeling strategy was used to investigate dose adjustment recommendations for amlodipine during and after co-administration of RTV containing 2- or 3-DAA regimens. Unlike previously published PBPK models for amlodipine [20,21], which did not confirm the extent and contribution of CYP3A4-mediated clearance, the model developed here is compared against dedicated clinical DDI studies with ritonavir. A PBPK model to be used to predict DDI pertaining to a particular metabolic pathway needs to be adequately qualified and verified for that intended purpose and verification of the fractional contribution of the particular pathway is a critical aspect [14]. This has been pointed out in PBPK guidance documents from regulatory agencies (United Stated Food \& Drug Administration [56], European Medicines Agency [57]). The developed PBPK model described the interaction over time between amlodipine and RTV, and simulations suggested that the 5-day window for returning to a full dose of amlodipine was largely due to time-dependent inhibition of CYP3A4 by RTV. Model simulations suggest that continuing with a reduced amlodipine dose for 5 days after a RTV regimen results in a $29 \%$ decrease in the average plasma concentration of amlodipine (on the 5th day after the last dose of RTV). On the contrary, resuming a full dose of amlodipine immediately after a RTV regimen results in a $26 \%$ increase in the average plasma concentration of amlodipine (on the 3rd day after the last dose of RTV). A local sensitivity analysis of the PBPK model was conducted, and the results (Fig. S6) suggest that plasma $\mathrm{C}_{\max }$ was most sensitive to the absorption rate constant $\left(k_{a}\right)$ and CYP3A4 intrinsic clearance $\left(C L_{\text {int }}\right)$. This is expected because rate of absorption and CYP3A4 clearance in the GI tract influences the initial plasma concentrations of amlodipine. Volume of distribution $\left(V_{d}\right)$ and volume of the single adjusting compartment $\left(V_{S A C}\right)$ were also sensitive parameters for $\mathrm{C}_{\max }$. Sensitivity analysis also suggests that AUC was most sensitive to the clearance processesCYP3A4 mediated and non-specific clearance. The PBPK model was developed using a 1st order absorption model and a minimal distribution model because amlodipine is considered a BCS class I compound with high solubility and permeability, and plasma and hepatic exposures are sufficient to characterize its efficacy and DDI. One of the limitations of the current 1 st order absorption and minimal distribution parts of our PBPK model is that it cannot be used to predict changes in plasma concentrations of amlodipine due to changes in formulation characteristics such as dissolution or to predict distribution to other tissues other than the liver, blood and the GI tract. However, the current amlodipine model serves the intended purpose of predicting DDIs with concomitant CYP3A modulators to inform dose adjustment decisions, and may be expanded to other applications if more data become available to inform for example changes in pharmaceutics characteristics. Model predicted $\mathrm{C}_{\max }$ for the IV dose was significantly under-predicted compared to the observed data reported by Faulkner et al. [32]. This might be due to the fact that the amlodipine PBPK model developed in Simcyp assumes a minimal distribution model where the drug entering venous blood instantly reaches equilibrium with the entire venous blood volume, while in reality plasma concentrations entering the vein might not equilibrate quickly due to the drug entering low perfusion tissues such as fat/skin/muscle. A full PBPK model could be used to evaluate this under prediction of $\mathrm{C}_{\max }$, however, it was not selected in this work since amlodipine is not known to have transportermediated processes that may influence drug distribution and tissue distribution data and partition coefficients for amlodipine are not available. There were also limitations to the accurate measurement of amlodipine venous blood concentrations at the very early time points after IV dose administration, as pointed out by Faulkner et al. [32], where these early plasma concentration time points were estimated by linear extrapolation and not measured directly, thus adding to the uncertainty in predicting the early plasma concentrations.

The developed PBPK model for amlodipine was further linked to a PD model for SBP. Simcyp ${ }^{\circledR}$ allows the development of mechanistic PBPK models; however, PD modules linked to such PBPK models have traditionally been simple linear or non-linear models. In this article, development of a complex PD model including a diurnal baseline effect has been described utilizing the Lua scripting facility in Simcyp ${ }^{\circledR}$. The diurnal model allows one to capture the dynamic oscillation in SBP, which is important for managing cardiovascular risk. For example, the nocturnal decline in SBP and the morning surge are important predictors of various cardiovascular events [52]. Based on the final PBPK/PD model simulations, amlodipine at a reduced dose of $2.5 \mathrm{mg}$ QD may be continued for 5 days after the last dose of RTV, followed by a return to the full dose of $5 \mathrm{mg}$ QD. Alternatively, the full dose of amlodipine may resume immediately, the day after the last dose of RTV. The PBPK/PD model predicted a maximum difference of 3-6 mmHg between the 2 dosing scenarios. However, the difference was greater $(10.6 \mathrm{mmHg})$ for a higher dose level of amlodipine (10 mg QD). Thus model predictions suggest that patients on a higher dose regimen of amlodipine are more vulnerable to changes due to dose adjustment. The difference in average daily SBP also does not reflect diurnal variations in SBP, which may lead to more significant variations. Based on the model predicted dynamic SBP (scenario 2), continuing with a reduced 
amlodipine dose for 5 additional days leads to a maximum SBP of $149.9 \mathrm{mmHg}$. Conversely, switching immediately to the regular amlodipine dose leads to a minimum SBP of $119.9 \mathrm{mmHg}$. For an individual on a regular amlodipine dose of $10 \mathrm{mg}$ QD (scenario 3), the predicted dynamic SBP reaches a low of $98.5 \mathrm{mmHg}$, which might be a critically low blood pressure. Blood pressure is also dependent on several other factors such as diet, sleep, stress levels and others. The model considers SBP due to amlodipine PK and hence the predictions do not preclude careful clinical monitoring for sudden changes in blood pressure, which might be influenced by other factors and hence difficult to predict using a non-mechanistic PD model. Physiological blood pressure control is a complex process involving the baroreflex loop, autoregulation, or by the renin-angiostenin-aldosterone system [20]. It is affected by food, sleep, stress, and multiple other environmental and genetic factors. The PD model does not consider any of these mechanisms or factors and is therefore limited in its predictive power of actual blood pressure under a variety of conditions.

Effects of disease, age, and co-medications on drug disposition are not additive and cannot always be predicted in a dynamic fashion. Given that amlodipine is commonly co-prescribed with other drugs, the PBPK/PD model developed here may serve as a future tool to simulate various dosing scenarios with and without DDIs with other CYP3A modulators. Another potential utility of the developed PBPK/PD model is that it may also be used to simulate plasma exposures in special populations such as elderly and cirrhotic populations with associated changes in hepatic clearance. The amlodipine PBPK/PD model may be useful in guiding dose adjustment in a variety of scenarios involving amlodipine.

Acknowledgements The authors thank AbbVie employees Karen E. Rynkiewicz for help with data collection from the literature and Allison M. Kitten for proofreading, editing, and formatting the article.

Funding The study was sponsored by AbbVie, Inc. AbbVie contributed to the study design, research, and interpretation of data, and the writing, reviewing, and approving of the publication.

\section{Compliance with ethical standards}

Conflict of interest DM, JZ, RMM, and MS are employees of AbbVie Inc. and may hold AbbVie stock or stock options.

Open Access This article is distributed under the terms of the Creative Commons Attribution 4.0 International License (http://creative commons.org/licenses/by/4.0/), which permits unrestricted use, distribution, and reproduction in any medium, provided you give appropriate credit to the original author(s) and the source, provide a link to the Creative Commons license, and indicate if changes were made.

\section{References}

1. IMS Institute for Healthcare Informatics (2011) The use of medicines in the United States: review of 2010

2. Levine CB, Fahrbach KR, Frame D, Connelly JE, Estok RP, Stone LR, Ludensky V (2003) Effect of amlodipine on systolic blood pressure. Clin Ther 25(1):35-57

3. USFDA (2001) Norvasc-clinical pharmacology \& biopharmaceutics review

4. Norvasc(R) (1987) (Amlodipine Besylate)—US Product Information, Pfizer Pharmaceuticals, New York, NY. http://www. accessdata.fda.gov/drugsatfda_docs/label/2011/019787s047lbl.pdf. Accessed Mar 2016

5. Viekira Pak(R) - US Product Information, AbbVie Inc., North Chicago, IL. http://www.accessdata.fda.gov/drugsatfda_docs/ label/2014/206619lbl.pdf. Accessed Mar 2016

6. University of California SF (2017) HIV InSite. http://hivinsite. ucsf.edu/InSite?page=md-rr-23. Accessed 9 Jan 2017

7. Viekirax(R) - Summary of Product Characteristics, AbbVie Inc., North Chicago, IL. http://ec.europa.eu/health/documents/commu nity-register/2015/20150115130406/anx_130406_en.pdf. Accessed Mar 2016

8. Kaletra(R)-US Product Information, AbbVie Inc., North Chicago, IL. https://www.accessdata.fda.gov/drugsatfda_docs/label/ 2016/021251s052_021906s046lbl.pdf. Accessed Aug 2017

9. Culm-Merdek KE, von Moltke LL, Gan L, Horan KA, Reynolds R, Harmatz JS, Court MH, Greenblatt DJ (2006) Effect of extended exposure to grapefruit juice on cytochrome P450 3A activity in humans: comparison with ritonavir. Clin Pharmacol Ther 79(3):243-254

10. Kirby BJ, Collier AC, Kharasch ED, Whittington D, Thummel KE, Unadkat JD (2011) Complex drug interactions of HIV protease inhibitors 1: inactivation, induction, and inhibition of cytochrome P450 3A by ritonavir or nelfinavir. Drug Metab Dispos 39(6): 1070-1078

11. Glesby MJ, Aberg JA, Kendall MA, Fichtenbaum CJ, Hafner R, Hall S, Grosskopf N, Zolopa AR, Gerber JG, Adult ACTGAPT (2005) Pharmacokinetic interactions between indinavir plus ritonavir and calcium channel blockers. Clin Pharmacol Ther 78(2):143-153

12. Menon RM, Badri PS, Wang T, Polepally AR, Zha J, Khatri A, Wang H, Hu B, Coakley EP, Podsadecki TJ, Awni WM, Dutta S (2015) Drug-drug interaction profile of the all-oral anti-hepatitis $\mathrm{C}$ virus regimen of paritaprevir/ritonavir, ombitasvir, and dasabuvir. J Hepatol 63(1):20-29

13. Rowland M, Peck C, Tucker G (2011) Physiologically-based pharmacokinetics in drug development and regulatory science. Annu Rev Pharmacol Toxicol 51:45-73

14. Wagner C, Zhao P, Pan Y, Hsu V, Grillo J, Huang SM, Sinha V (2015) Application of physiologically based pharmacokinetic (PBPK) modeling to support dose selection: report of an FDA public workshop on PBPK. CPT Pharmacomet Syst Pharmacol 4(4):226-230

15. Zhao P, Zhang L, Grillo JA, Liu Q, Bullock JM, Moon YJ, Song P, Brar SS, Madabushi R, Wu TC, Booth BP, Rahman NA, Reynolds KS, Gil Berglund E, Lesko LJ, Huang SM (2011) Applications of physiologically based pharmacokinetic (PBPK) modeling and simulation during regulatory review. Clin Pharmacol Ther 89(2):259-267

16. Freise KJ, Shebley M, Salem AH (2017) Quantitative prediction of the effect of CYP3A inhibitors and inducers on venetoclax pharmacokinetics using a physiologically based pharmacokinetic model. J Clin Pharmacol 57(6):796-804

17. Shebley M, Fu W, Pang Y, Bow DJ, Fischer V (2016) Assessment of drug-drug interaction potential between dasabuvir and 
clopidogrel using PBPK modeling and simulations: a case of successful regulatory submission using PBPK. Clin Pharmacol Ther 99(S1):S66

18. Varma MVS, Lai Y, Kimoto E, Goosen TC, El-Kattan AF, Kumar V (2013) Mechanistic modeling to predict the transporterand enzyme-mediated drug-drug interactions of repaglinide. Pharm Res 30(4):1188-1199

19. Moj D, Britz H, Burhenne J, Stewart CF, Egerer G, Haefeli WE, Lehr T (2017) A physiologically based pharmacokinetic and pharmacodynamic (PBPK/PD) model of the histone deacetylase (HDAC) inhibitor vorinostat for pediatric and adult patients and its application for dose specification. Cancer Chemother Pharmacol 80(5):1013-1026

20. Blei K (2015) Development of a physiologically-based model with a regulatory and excitable cardiovascular system. Jacobs University, Bremen

21. Dennison TJ, Smith JC, Badhan RK, Mohammed AR (2017) Fixed-dose combination orally disintegrating tablets to treat cardiovascular disease: formulation, in vitro characterization and physiologically based pharmacokinetic modeling to assess bioavailability. Drug Des Devel Ther 11:811-826

22. Caron G, Ermondi G, Damiano A, Novaroli L, Tsinman O, Ruell JA, Avdeef A (2004) Ionization, lipophilicity, and molecular modeling to investigate permeability and other biological properties of amlodipine. Bioorg Med Chem 12(23):6107-6118

23. McDaid DM, Deasy PB (1996) Formulation development of a transdermal drug delivery system for amlodipine base. Int $\mathbf{J}$ Pharm 133(1):71-83

24. Zhu Y, Wang F, Li Q, Zhu M, Du A, Tang W, Chen W (2014) Amlodipine metabolism in human liver microsomes and roles of CYP3A4/5 in the dihydropyridine dehydrogenation. Drug Metab Dispos 42(2):245-249

25. Beresford AP, McGibney D, Humphrey MJ, Macrae PV, Stopher DA (1988) Metabolism and kinetics of amlodipine in man. Xenobiotica 18(2):245-254

26. Jamei M, Marciniak S, Feng K, Barnett A, Tucker G, RostamiHodjegan A (2009) The Simcyp ${ }^{\circledR}$ population-based ADME simulator. Exp Opin Drug Metab Toxicol 5(2):211-223

27. Johnson TN, Zhou D, Bui KH (2014) Development of physiologically based pharmacokinetic model to evaluate the relative systemic exposure to quetiapine after administration of IR and XR formulations to adults, children and adolescents. Biopharm Drug Dispos 35(6):341-352

28. Rausl D, Fotaki N, Zanoski R, Vertzoni M, Cetina-Cizmek B, Khan MZ, Reppas C (2006) Intestinal permeability and excretion into bile control the arrival of amlodipine into the systemic circulation after oral administration. J Pharm Pharmacol 58(6):827-836

29. Flynn JT, Nahata MC, Mahan JD Jr, Portman RJ (2006) Population pharmacokinetics of amlodipine in hypertensive children and adolescents. J Clin Pharmacol 46(8):905-916

30. Stopher DA, Beresford AP, Macrae PV, Humphrey MJ (1988) The metabolism and pharmacokinetics of amlodipine in humans and animals. J Cardiovasc Pharmacol 12(Suppl 7):S55-S59

31. Meredith PA, Elliott HL (1992) Clinical pharmacokinetics of amlodipine. Clin Pharmacokinet 22(1):22-31

32. Faulkner JK, McGibney D, Chasseaud LF, Perry JL, Taylor IW (1986) The pharmacokinetics of amlodipine in healthy volunteers after single intravenous and oral doses and after 14 repeated oral doses given once daily. Br J Clin Pharmacol 22(1):21-25

33. Poulin P, Theil FP (2002) Prediction of pharmacokinetics prior to in vivo studies. 1. Mechanism-based prediction of volume of distribution. J Pharm Sci 91(1):129-156

34. Berezhkovskiy LM (2004) Volume of distribution at steady state for a linear pharmacokinetic system with peripheral elimination. J Pharm Sci 93(6):1628-1640
35. Shebley M, Liu J, Kavetskaia O, Sydor J, de Morais SM, Fischer V, Nijsen MJ, Bow DA (2017) Mechanisms and predictions of drug-drug interactions of the hepatitis $\mathrm{C}$ virus 3-direct acting antiviral (3D) regimen: paritaprevir/ritonavir, ombitasvir and dasabuvir. Drug Metab Dispos 45:755-764

36. Barter ZE, Tucker GT, Rowland-Yeo K (2013) Differences in cytochrome p450-mediated pharmacokinetics between chinese and caucasian populations predicted by mechanistic physiologically based pharmacokinetic modelling. Clin Pharmacokinet 52(12): 1085-1100

37. Jamei M, Dickinson GL, Rostami-Hodjegan A (2009) A framework for assessing inter-individual variability in pharmacokinetics using virtual human populations and integrating general knowledge of physical chemistry, biology, anatomy, physiology and genetics: a tale of 'bottom-up' vs 'top-down' recognition of covariates. Drug Metab Pharmacokinet 24(1):53-75

38. Rostami-Hodjegan A, Tucker GT (2007) Simulation and prediction of in vivo drug metabolism in human populations from in vitro data. Nat Rev Drug Discov 6:140

39. Barter ZE, Bayliss MK, Beaune PH, Boobis AR, Carlile DJ, Edwards RJ, Houston JB, Lake BG, Lipscomb JC, Pelkonen OR, Tucker GT, Rostami-Hodjegan A (2007) Scaling factors for the extrapolation of in vivo metabolic drug clearance from in vitro data: reaching a consensus on values of human microsomal protein and hepatocellularity per gram of liver. Curr Drug Metab $8(1): 33-45$

40. Yang J, Liao M, Shou M, Jamei M, Yeo KR, Tucker GT, Rostami-Hodjegan A (2008) Cytochrome p450 turnover: regulation of synthesis and degradation, methods for determining rates, and implications for the prediction of drug interactions. Curr Drug Metab 9(5):384-394

41. Park SM, Lee, J., Seong, S., Lim, M., et al. (2016) Population pharmacokinetics of S-amlodipine in healthy Korean male subjects. Poster-PAGE meeting 2016, Lisbon, Portugal

42. Faulkner JK, Hayden ML, Chasseaud LF, Taylor T (1989) Absorption of amlodipine unaffected by food. Solid dose equivalent to solution dose. Arzneimittelforschung 39(7):799-801

43. Williams DM, Cubeddu LX (1988) Amlodipine pharmacokinetics in healthy volunteers. J Clin Pharmacol 28(11):990-994

44. USFDA (2001) Guidance for industry-statistical approaches to establishing bioequivalence

45. Laher MS, Kelly JG, Doyle GD, Carmody M, Donohoe JF, Greb H, Volz M (1988) Pharmacokinetics of amlodipine in renal impairment. J Cardiovasc Pharmacol 12(Suppl 7):S60-S63

46. Donnelly R, Meredith PA, Miller SH, Howie CA, Elliott HL (1993) Pharmacodynamic modeling of the antihypertensive response to amlodipine. Clin Pharmacol Ther 54(3):303-310

47. Byyny RL, Shannon T, Schwartz LA, Rotolo C, Jungerwirth S (1997) Efficacy and safety of nifedipine coat-core versus amlodipine in patients with mild to moderate essential hypertension: comparison of 24-hour mean ambulatory diastolic blood pressure. J Cardiovasc Pharmacol Ther 2(2):77-83

48. Calvo C, Gude F, Abellán J, Oliván J, Olmos M, Pita L, Sánz D, Sarasa J, Bueno J, Herrera J, Macías J, Sagastagoitia T, Ferro B, Vega A, Martínez J (2000) A comparative evaluation of amlodipine and hydrochlorothiazide as monotherapy in the treatment of isolated systolic hypertension in the elderly. Clin Drug Investig 19(5):317-326

49. Canale C, Terrachini V, Masperone MA, Caponnetto S (1991) Open comparative study to assess the efficacy and safety of two calcium antagonists: amlodipine and diltiazem in the treatment of symptomatic myocardial ischemia. J Cardiovasc Pharmacol 17(Suppl 1):S57-S60

50. Frishman WH, Brobyn R, Brown RD, Johnson BF, Reeves RL, Wombolt DG (1994) Amlodipine versus atenolol in essential hypertension. Am J Cardiol 73(3):50A-54A 
51. Degaute JP, van de Borne P, Linkowski P, Van Cauter E (1991) Quantitative analysis of the 24-hour blood pressure and heart rate patterns in young men. Hypertension 18(2):199-210

52. White WB (2007) Importance of blood pressure control over a 24-hour period. J Manag Care Pharm 13(8 Supp B):34-39

53. Sällström B, Visser SAG, Forsberg T, Peletier LA, Ericson A-C, Gabrielsson J (2005) A pharmacodynamic turnover model capturing asymmetric circadian baselines of body temperature, heart rate and blood pressure in rats: challenges in terms of tolerance and animal-handling effects. J Pharmacokinet Pharmacodyn 32(5):835-859
54. Gabrielsson J, Weiner D (2015) Pharmacokinetic and pharmacodynamic data analysis: concepts and applications. Apotekarsocieteten, Stockholm

55. Abduljalil K, Edwards D, Barnett A, Rose RH, Cain T, Jamei M (2016) A tutorial on pharmacodynamic scripting facility in Simcyp. CPT Pharmacomet Syst Pharmacol 5(9):455-465

56. USFDA (2016) Physiologically based pharmacokinetic analyses-format and content-guidance for industry

57. EMA (2016) Guideline on the qualification and reporting of physiologically based pharmacokinetic (PBPK) modelling and simulation. London 